\title{
[4]
}

\section{The Changing Political Economy under the Nationalists}

With the arrival of the Nationalists, the island's closely linked political and economic systems underwent major changes, which kept Taiwan poorer for fifteen years than it had been in the prosperous thirties under the Japanese. Between 1945 and 1950, economic goals were first reoriented away from the Japanese empire and toward China's mainland. Then, with the collapse of Nationalist power there, the system floundered, surviving on American aid and a limited range of indigenous products and markets. Both Taiwanese and low-ranking Mainlanders remember these mostly as hard years, though for a few, money flowed freely from smuggling, graft, or postwar rebuilding.

\section{Economic Development}

Among the immigrants who arrived in Taiwan after 1949, some pressed for reforms, particularly in agriculture. Under pressure from the United States, Jiang gave these land reformers permission to reorganize Taiwan's landholdings under a program that liberal Nationalists had long advocated for the mainland, though never put into action. Under the reform, complete by 1953, farmland in excess of three hectares ( 7.2 acres, enough for a family farm) was bought from landlords by the government, paid for with government bonds and stocks in government companies. It was resold on ten-year mortgages at an annual rate of 37.5 percent of its annual crop value 
to families with less than that quantity of land, tenants being given the first right to purchase (Chen 1961; Yang 1970). Landlords hated the policy, for government investments seemed very shaky in the early 1950s; frightened by the events of 1947 , however, they did not protest. Nevertheless, they thought up as many schemes as they could to avoid having to sell their land, such as dividing it up legally among many family members. By contrast, the reform was popular with tenants and greatly improved the prestige of the Nationalist party in the countryside. The land reform secured Nationalist rule in Taiwan both by undercutting the power of landlords and by ensuring support from the much larger group of new owner-operators.

This major change in ownership of the primary means of production greatly affected rural life in Taiwan. Farmers did not become rich from owning their own land, for Nationalist taxes, direct and indirect, soon ate up most of the gain made on rent; but about two-fifths of former tenants built new houses, many families ate a bit better (Yang 1970:276-88), and some found the capital to go into small businesses that did produce a higher income. The reform, moreover, had other important long-term consequences. By keeping landholdings small, the policy meant that many farm children would have to leave the land and go into other occupations. This created a pool of cheap labor for industry when it began to expand. The small size of farms meant also that their mechanization was difficult, constraining most farmers to continue to rely on the cheapest and most available of labor, their own large families. These pressures and government tax and pricing policies kept farmers poorer than the rest of the population, made young people want more than ever to escape farm life, and encouraged explosive population growth in Taiwan during the fifties and sixties (Hsiao 1981; Huang S. 1981). By the early seventies, many farm households depended heavily on nonagricultural income to get by (Wang and Apthorpe (1974:13).

While the land reform brought some immediate benefits, the Nationalist-run economy did very poorly in Taiwan beginning with their arrival in 1945 until the early sixties. Chinese rule brought terrible inflation to the island which did not stabilize until the mid-fifties, destroying people's savings and making business dealings risky. Between the wartime inflation of Japanese money and the unprecedented Nationalist expansion of currency, staple foods that cost one yen in prosperous prewar 1937 cost 72,262 units of Chinese currency by May 1949, and building materials inflated from one unit to 93,563 over the same period. Between January and June of 1949, the cost of living rose ten times (Kann 1955, IV:689). This was the result not only of "normal" wartime inflation, but of "the forced 
requisitioning, from August 19, 1948, onward, of foreign monies, gold and silver, against almost worthless paper, under false pretences, . . . a crime against the people" of China (Kann 1955, 1:595).

In Taiwan the government staffed large state enterprises with Mainlanders, who knew nothing about the businesses, as a reward for their services. These state enterprises lost money and were sources of corruption. Extremely complicated governmental control of trade slowed exports and imports, making it difficult to obtain raw materials. Access to large quantities of capital and credit depended on personal ties with the banking establishment, which eliminated most Taiwanese from competition. The heaviest burden on the economy was the huge military force that Jiang maintained in the ever-diminishing hope of retaking the mainland. Fourfifths of government income including the very large commitment of American aid to Taiwan in these years, went to the military, keeping the inflation rate high through the early sixties (Morgan Guaranty Survey 1962), and leaving little for social or economic development (Jacoby 1967:109).

In the 1960s Taiwan began to move to an industrial economy that soon successfully exported textiles, footwear, plastics, and electronics to the United States. This dramatic reversal was brought about by changes in leadership, by the cutoff of much of the American aid on which the Nationalists had long depended, by fears of being surpassed by the thenplausible gains of the Communist Great Leap Forward, and by a boom in foreign investment that brought private capital from the United States and Japan. Taiwan advertised itself abroad as having plenty of cheap and docile labor that was forbidden to strike. By the seventies, companies like Westinghouse, Sanyo, and Texas Instruments were well known in Taiwan, employing thousands of young men and women at wages of a few hundred dollars a year. Smaller businesses expanded in association with them, often capitalized initially from the earnings of workers in one of the big enterprises. Economic growth faltered occasionally, for the new dependence on exports has made Taiwan vulnerable to changes in the world-and especially the American-economy; but in general, growth has been both high and constant since the sixties. And in the early 1960s, urbanization brought so many people out of the countryside that more people were now living in cities than in rural areas.

As life became more prosperous, a consumer economy began to grow. By 1982, nearly 70 percent of Taiwan's households had telephones; these had required an installation fee equal to a worker's yearly wage when I arrived in 1968. Ninety-five percent had refrigerators, which only the salaried middle and upper classes could afford in 1968 (and which they then displayed proudly in their living rooms.) Eighty-five percent had color 
television, 90 percent had motorcycles, and over 7 percent owned private cars-a luxury in a country where the public transportation network is so complete (Free China Journal, July 1, 1984:4). People ate noticeably better, bought Japanese-styled "Western" clothes, supported more children through longer educations, and had more money to save and invest.

Life in Taibei astonished me when I arrived in 1980 and compared what I saw with pictures and memories of 1968 and even of 1975. My first impression (and the only impression for most visitors) was of great wealth. I saw young men playing ice hockey in a twelfth-floor amusement complex, immense traffic jams of private cars, dresses costing hundreds of dollars in chic boutiques, and street after street of expensive, brand-new condominiums. Billboard ads offered villas in the mountains, and pricey Japanese-style restaurants were flourishing. Where in 1968, on a very small student scholarship, I had been able to afford a comfortable bungalow with its own yard, a full-time housekeeper, and occasional visits to the best restaurants in the city, now as a full-time university professor I found that many of these things in Taibei, as in New York or Tokyo, were quite out of my price range. It was an interesting reversal.

When I began my interviewing for the life histories, however, I soon discovered that for some of my old friends life had not changed much. A few had become fairly well-off and moved to fancier neighborhoods where they worried about parking and getting their youngsters into the "right" schools. Most, though, lived much as they had, their biggest acquisitions being better diets, a few more clothes, a color television, and a motorcycle. They still experienced crowded quarters, long hours of work, little economic security, and what most Americans would consider a very simple life style. They talked with me a great deal about the wealth they saw in their city, and sometimes lamented that they had not had the luck or cleverness to get rich. Chinese people love to poor-mouth themselves, so I did not take some of their complaints literally-it often turned out they had significant sums in the bank or lent out at interest - but it was clear as I reexplored the city and countryside that there were many people who had benefited very little from the economic miracle. As they said, "kun do li ci" (T) - "We get by."

Another side of life that has not changed greatly is politics. The rule of the Nationalists in Taiwan was harsh in the beginning both because they had developed a repressive style of government on the mainland, and because their main goal - to retake the mainland-required the subordination of the needs of the island's people to those of high Nationalist leaders for power over resources. By continuing to maintain the fiction that they are the government of all China, even their representative elective institutions have remained biased against native Taiwanese participation and power 
holding. Strongly repressive measures are necessary to preserve this unequal situation against the pressures of the large and increasingly prosperous Taiwanese majority.

\section{Ethnicity and Social Class}

Although the social fracture between Taiwanese and Mainlander has healed somewhat, especially among those born since the economic boom began, Taiwanese at all levels of society resent their political inequality and the harsh measures used to maintain it. Those who would actively oppose the Nationalist claim of being a central government for all of China were long forbidden to put forth an alternative political position or to form an opposition party. In 1986, Taiwanese oppositionists formed such a party, although its legality remains open to question. But though it has been difficult to institutionalize the ethnic distinction in politics, working-class people remain conscious of their own and others' regional origins in daily life as they speak different languages, follow different customs, and link into different social networks. Ethnicity remains a meaningful category for most people. Social class distinctions, though less well articulated, also operate in Taiwan. To be born working-class or elite, Taiwanese or Mainlander, makes a considerable difference to an individual's life circumstances and future fortunes.

The existence of classes and ethnic categories in a society creates a degree of cultural complexity much greater than that seen in egalitarian, small-scale societies. For social scientists, therefore, ethnicity and class are important concepts, but they are also complicated and controversial ones because they are among the commonest means by which people in complex societies are manipulated politically and economically, and by means of which they resist such manipulation. Individuals, social groups, and powerful organs of the state have interests in shaping what ethnicity and class will mean, and in using these concepts for political ends. On these matters, there is no such thing as an "objective" viewpoint, even for an outsider; any viewpoint has political implications.

Ethnicity does not derive only from the persistence of historical cultural elements in an ethnic group, even if that group's members perceive these as badges of identity. Some groups, in the process of adaptation to new conditions, abandon virtually all customs, traditions, languages, and characteristic forms of social relations that historically marked their culture of origin, as the great majority of Americans have done. Nevertheless, ethnicity may persist as a matter of self-identification, as for the large 
numbers of completely assimilated American Irish, Jews, and Poles. Such people enjoy a sense of being connected to the past which, however, affects their cultural behavior hardly at all. And under some circumstances, such ethnic identities are optional: by changing a surname, Americans of European background can, if they choose, drop their ethnic identity and join the cultural mainstream. (This is obviously much more difficult for Americans whose physical appearance suggests a non-European origin.)

Ethnicity has a very different meaning in societies where it has become an official identity, and where ethnic groups do not receive equal treatment under the law and in society. Although the limitations imposed on Taiwanese to the benefit of Mainlanders are less serious than those placed on Jews by Germans under Hitler or on Blacks by precivil-rights-era Americans and in contemporary South Africa, they have nevertheless made ethnicity an important and persistent factor in Taiwan's social organization.

Each of Taiwan's citizens inherits a hereditary identity based on province of origin from his or her father-the mother's identity is irrelevant except in cases of illegitimacy. This provincial identity is indicated in household registrations and on the identity card that every adult must carry when in public. Until the sixties, children in school were often asked at the beginning of the school term to indicate their provincial identity for their classmates. Asking after a new acquaintance's "old home" is a common conversational opener. Many people identify themselves as soon as they speak, by language or accent, and even certain haircuts and clothing styles are associated with particular groups. Ethnic identities are thus frequently apparent in ordinary life, and older people are generally highly conscious of their own and others' ethnicities. Because Mainlanders are in substantial numerical minority (about one-tenth of the population), the Taiwanese usually collapse them into a single category; among Mainlanders, however, the distinctions between for example, a Cantonese and a Shandongnese are still significant.

The authorities continue to identify persons by their provinces of origin in part because the Nationalist government, still claiming to be the government of all of China, wishes to remind islanders that their government represents the mainland as well. There have been practical reasons, too, for some people to adopt strong ethnic identities and impose them on others. In the early years of Nationalist rule in Taiwan, being a Mainlander gave one a distinct advantage in getting government jobs, while being Taiwanese often sufficed for being fired from one. Mainlanders today justify their earlier, harsher discrimination by noting that Taiwanese were ignorant of the national language in which government business was transacted. This is reasonable enough, except that a good many Mainlanders from the south 


\section{Chinese Working-Class Lives}

also speak Mandarin almost incomprehensibly, or not at all. In any case, a good deal of technical business in government departments where Taiwanese were able to hold their jobs continued to be conducted in Japanese into the seventies. More important than language skills was the reality that Nationalist leaders retained the loyalty of those who had followed them to Taiwan by giving them government jobs, preferring their minority government to be in the hands of their own people instead of those of the increasingly hostile Taiwanese. The number of Taiwanese that the government employed decreased steadily from 77 percent in 1946 to its lowest point at 61 percent in 1962 (Gates 1981:257). As long as government and military positions remained in Mainlander hands, the Taiwanese could be controlled.

But government work, schoolteaching, post-office jobs, and the like constituted the choicest occupations in Taiwan during that stagnant period from the destruction of the thirties' prosperity to the new industrialization of the sixties. Mainlander discrimination kept the Taiwanese confined to agriculture and small business in the forties and fifties, a situation that perpetuated Taiwanese resentment and sense of separation.

While Mainlanders effectively monopolized official occupations, a stereotype arose that commerce and industry were the special occupational niche of Taiwanese because their many small businesses, and a few successful large ones, were so visible. In fact, Mainlander businesses founded with the capital, machines, expertise, and political contacts of Shanghai capitalists also flourished, giving Mainlanders a disproportionate share of the private enterprises, almost one-third of the largest one hundred corporations in 1973 ([American Embassy Staff? 1973?]). Perhaps because Taiwanese business expanded so rapidly after the sixties, and perhaps, as Mainlanders argue, because the Taiwanese owned the land, they came to be seen as people with money, or at least as having the means of making it. Ethnic identities became strongly tinged with assumptions about occupation.

Linked patterns of language use and education also promoted the separation of Taiwanese and Mainlander ethnic groups. When the Japanese moved out of their elite neighborhoods and schools in Taibei, Mainlanders moved in. Although schools were never legally segregated by provincial origin, Mainlander communities often had their own schools, either inherited from the Japanese or specially built for military families, where all the children were Mainlanders learning standard Mandarin from Mandarinspeaking teachers. This handicapped the non-Mandarin speaking children in their pursuit of education. With the shift to Mandarin, it became difficult for Taiwanese to transact official business because of the language barrier. 
On my first visit, I sometimes heard teenage girl ticket takers on the public buses scold elderly Taiwanese men simply for trying to purchase tickets in the wrong language. Taiwanese culture was seen as lower class and in need of reform-a view that some Taiwanese accepted humbly and others resented deeply because it came from authorities who at the same time insisted that the Taiwanese be loyal Chinese.

As time passes, the government increasingly plays down the distinctions between Taiwanese and Mainlanders. People accustomed to thinking politically-mostly the educated elite-are intensely aware that to stress the distinction casts doubt on the unity of the population behind its largely Mainlander government. To suggest that the population does not support the government comes extremely close to disloyalty, so discussion of Taiwanese-Mainlander differences is avoided. This does not mean that the distinction has become unimportant. In the life stories of my working-class subjects, being Taiwanese or Mainlander constitutes part of each person's primary identity; the language barrier alone causes feelings of separateness among older people, as do their different attitudes toward the Japanese, the Nationalist government, and many local customs. At the same time, the life histories contain examples-such as Miss Guo and her "old lover"-of married couples who have managed a lifetime and several children together despite ethnic differences. There are many such families.

Younger people, born in Taiwan, have a less clear-cut view of these ethnic identities, especially those born to mixed Taiwanese and Mainlander parents. But the stereotyped beliefs that Mainlanders have an easier road into the upper levels of government service, the military, and academic life while the Taiwanese monopolize commerce and industry are not without foundation. Mr. Zhang and Mr. Kang, after a life spent under the shelter of government service, would feel demeaned to work in a Taiwanese business, even if they could find a Taiwanese who would hire them; and there are no Taiwanese dead among the hundreds of young Air Force officers with whom Mrs. Zhang's son is buried.

When we turn to the understanding of social class in Taiwan's society, we face a more complex problem than that of ethnicity. "Class" means many things in social science, sometimes referring to a stratum in a kind of social layer cake hierarchically arranged by either wealth or prestige. Layer-cake analyses are always flawed, for in a society that is undergoing any change at all, rankings by wealth and by prestige often do not coincide. An even greater drawback of the layer-cake approach to class is the reality that ranking people in society by wealth and prestige is a closed exercise. Such rankings, in and of themselves, tell us nothing about why some groups rank higher than others, why change occurs in such systems, or indeed anything 


\section{Chinese Working-Class Lives}

else at all about the society in question. Understanding class categories should generate insights about the dynamics of the relationships among these unequal categories: how social inequalities emerged, are maintained, and may be reproduced.

To analyze social class, one may employ the cultural categories used by the people themselves. In Taiwan, although ethnicity is a much-used cultural category among working-class islanders, social class is not, although people do refer frequently to the rich and the poor, and to those who have or have not "received education," as different and unequal strata in society. For some social analysts, the fact that these people do not explicitly define classes within their society and identify with one of them-that they have no "class-consciousness"-means that Taiwanese society cannot be said to be organized into classes. Such an approach is unhelpful because the analyst expects, unrealistically, that the people under study will discuss their own society perfectly freely and in socialscience terms. These life histories, however, reveal their subjects to be conscious of social categories-rich and poor, educated and uneducated, Mainlander and Taiwanese-that clearly imply organized inequality even though they do not describe it in terms of "class."

Additionally, people in Taiwan are not free to analyze their society in class terms, because this is what the government's great rivals, the Communists, do. Careful censorship of the written word and school classrooms has effectively deleted the term from discourse.

A different line of argument holds that Taiwan's people are conscious of class, but in a distorted way. Because ethnic differences are so apparent and the conflict between Mainlanders and Taiwanese has sometimes been so sharp, many people see ethnicity as the dominant form of inequality in their society, while class relationships are less clearly seen. Many of the people in the life histories, both Taiwanese and Mainlanders, made it clear to me that they believe their society is structured into two ranked categories, with their own ethnic group the victim of the other (Taiwanese feel oppressed by Mainlander domination of government and military, Mainlanders by Taiwanese wealth and business prominence). Each sees the other as "rich" and powerful, unlike themselves. This comes very close to a view of Taiwan's society as one in which ethnicity and social class coincide. However, it is also apparent from the life histories that the working class contains people of both ethnic groups, as does Taiwan's elite-and that everyone knows this.

Although Taiwan's society may indeed have been organized into two unequal ethnic strata just after Retrocession-since the mid-sixties when opportunities began to expand for everyone--this is no longer the case. It is 
not surprising that working-class Taiwanese should remember the former Mainlander dominance, while working-class Mainlanders are struck by the way Taiwanese have come up in the world of business.

Although both Taiwanese and Mainlanders sometimes speak of their own group as if it were homogeneous and are therefore likely to see social relations in ethnic terms, they are also conscious of a kind of ranking that crosscuts ethnic categories- "rich people" and "educated people" versus "poor people" and "uneducated people." Miss Guo is quite explicit that "rich people" would be unwilling to invite people like herself to join rotating credit clubs, for example. Mrs. Zhang sees her fellow Shandongnese employer as rich, powerful, and educated compared with herself, despite their common ethnicity. Although neither would use the term "class" to make this distinction, they make the distinction nonetheless. Taiwan's people, it seems to me, are conscious not only of ethnic hierarchy but of class differences as well, though working-class people often assume the two coincide.

Attending to what these people say about social inequality in Taiwan is essential to understanding that society, but native views alone can fruitfully be supplemented with other forms of analysis which will link patterns of inequality to other aspects of the culture-if we are careful to specify what we mean by class.

The concept of class has its greatest utility when we use it as Marxists do to categorize people's relationships to the society's political-economic system. Fundamentally, this approach asks: How are people connected to society's most basic resources, the means of production? In an industrial capitalist society, the means of production include land, tools, factories and their productive machinery, raw materials for industrial use, and money capital. People in such societies either own these means of production, and can be called the capitalist class or bourgeoisie, or they own no means of production but sell their labor to those who do, and can be called the working class or proletariat. The part of the working class that labors in modern, technologically advanced industry is particularly significant because the greatest wealth and economic dynamism are concentrated there. The relationship between workers and capitalists affects the course of history most deeply because the owners of capital struggle to control the workers, and the workers struggle to control their own lives.

These, therefore, are society's most significant classes. There are, of course, other categories of people-white-collar workers, an underclass of permanently unemployed and criminal elements, intellectuals, and so forth, but they are peripheral to the real issue: Who will control society's most productive resources-capitalists, whose primary goal must be the 
expansion of capital by the making of profit, or workers, whose primary goals are secure employment and maintenance or improvement of their families' lives? Other groups, whatever their rankings in wealth or prestige, do not matter very much except as they line up on one side or the other of the power struggle between the workers and the capitalists. We need not build a layer-cake model that includes all social groups to understand class relations in a particular capitalist society; we must only pinpoint who, in that society, owns the means of production and lives from profit, and who sells the labor that operates production and lives from wages.

This model of society and its fundamental source of change is not a perfect one, especially for countries with governments that employ many people independently of private capitalists. In Taiwan, with its overscaled national government (intended for all of China) and military and its many state-run enterprises, the state itself is a major owner of important means of production; the petroleum, coal, electric, railroad, cement, and sugar businesses, to name a few, are state enterprises. Workers in such businesses-civil servants, schoolteachers, and career military officers-have a strong interest in the maintenance of the public power that protects private and public enterprises against other workers' attempts to gain power.

The model of social class that depends heavily on defining each group's relationship to the means of production also applies with difficulty to the myriads of small business people and farmers who form a large part of Taiwan's population and an important part of its economy. Are they capitalists or workers? They own their own means of production, but they also provide most of their own labor needs, so they do not, as capitalists do, live from profits drawn from the work of others. And, in Taiwan's complex, mixed economy, small business people need access to important means of production which they do not control. Where, for example, a family subcontracts to a large factory to finish sweaters, its members differ from the factory's own workers only in that they supply their own workplace, perhaps purchase some of the necessary raw materials, and work according to their own schedules. Otherwise, they are simply selling their laborusually rather cheaply, saving the factory owner his overhead costs.

In nineteenth-century European societies of the early industrial revolution, this "petty bourgeoisie" of small producers and shopkeepers was likely, in the political struggle, to line up with the big capitalists, and to be political enemies to the workers' cause. In Taiwan, the alliances seem to be different. Small business people, especially among the Taiwanese, form their closest ties with their laboring neighbors through kinship, neighborship, and community rituals. Members of small business families often work in factories or other clearly "working-class" jobs. People in this class 
are fully aware that they are "little people" in a society that also has wealthy and powerful people far "above" themselves. On the other hand, even the smallest entrepreneur sometimes dreams of making it big and rising into the class of big capitalists, and laborers dream of noodle stands of their own. Neither, in my opinion, would politically support the elimination of the opportunities they believe capitalism offers them, but both, in their daily lives, identify strongly with the "poor" and "uneducated" that comprise most of Taiwan's working class.

In short, in this society where relatively few people own or control major means of production, the ownership of a tiny shop or business does not separate a family enough from its laborer neighbors to cause differences in political orientation, although many older Mainlander immigrants still identify more with their fellow-ethnic government employers than with the working-class majority. At the same time, the gap in productivity between working-class people and those who own, control, or manage large-scale modern industries is a large and real one that ordinary people perceive as the result of differences in wealth and education.

Societies such as those in Taiwan, imperial China, and the United States are variously described as "state level," "complex," or "class" societies. Their distinguishing characteristics are the persisting inequalities between classes (and, sometimes, ethnic groups) and a centralized government with the power to set many of the political, economic, and cultural conditions under which these unequal segments relate to one another. Class societies vary greatly in the degree to which individuals and families can move from one class to another, and in the degree of forcible control that the government exercises to maintain a pattern of relations among classes. Nevertheless, because class relations and state power always shape class societies, politics at the national level, and possibly the international level as well, are directly and immediately relevant to their cultures. This is so even when many members of that society, as in Taiwan, take little part or interest in politics.

Most of Taiwan's people are clearly materially better off now than they were during the best of Japanese times; many more have found nonmanual jobs; and a smaller number of workers than in the past now perform the most grueling kinds of manual labor. Social mobility has been both relative and absolute, and people know it. At the same time, inequalities persist. Differences in wealth, often a good indicator of other forms of inequality, are vast, ranging from the Jiang family, which had grown rich on the mainland through political influence and continued to do so in Taiwan, to families like Miss Ong's, whose ancestral land became valuable as the result of urban growth, to such men as Mr. Kang, who after a lifetime of service 


\section{Chinese Working-Class Lives}

and labor will not have enough to live on when he retires. Yet there are few overt signs, especially among the working class, that people resent or wish to eliminate these inequalities through political action.

A group's apathy rather than activism toward political processes that ultimately affect them requires considerable explanation. Anthropological studies show that people in cultures without social classes and centralized power typically participate vigorously and enthusiastically in their societies' decisions. When a significant proportion of a class society's population refrains from involvement in politics, we may at least suspect that the power of the state or of a dominant class discourages them from involvement.

\section{Repression and Resistance}

The most rapidly growing segment of Taiwan's economy since the sixties has been its industries. In modern industry we can see most clearly the connections among economic development, social class relations, and political power. Where a class confrontation between industrial workers and factory owners over wages, working conditions, and other mutual interests might have taken place, as it has in many industrializing countries, the Nationalist government interposed martial law, making it illegal to strike or to form independent unions. It is illegal to hold meetings of any kind without police permission, or to meet in educational groups to study socialist solutions to laborers' problems. Working people, who through experience in the new factories might have developed a consciousness of their own importance in the new industrial economy and tried to gain leverage from it, have not done so as industrial workers have done in less repressive industrial countries. Taiwan's industrial growth was built on cheap labor, which remained cheap because state power limited workers' power to organize in their own interests.

One can argue that, since cheap labor was very nearly the only resource Taiwan's battered fifties economy had to put on the international market, only by keeping the price of labor low did the country achieve the present greater prosperity. But Nationalist antiworker policies long preceded their 1960s seduction of foreign investors with promises of low labor costs in Taiwan. Having been driven out of China in 1949 by a coalition of workers and peasants, the Nationalists had learned to fear working-class strength. The government, committed not to democracy but to the concept of "political tutelage" of the population by the Nationalist party, found reasons to suppress, limit, or control virtually every kind of popularly developed 
social organization except for those focusing on kinship and folk religionand even some folk religions are outlawed and suppressed (Jordan 1972). Taiwan's police, secret police, intelligence, and other surveillance organs, large and ubiquitous, have received excellent training by American specialists and they now themselves train Salvadoran police in "population control." The island is small, escape routes few, and the household registration system enables the police to exert great pressure on relatives of fugitives to turn them in.

The Nationalists' profound distrust of social groups or movements they do not control has led to the banning of publishing groups, the imprisonment of students and teachers meeting privately to discuss politics, the infiltration of informers into all kinds of organizations, and even the suppression, in the mid-seventies, of a naively patriotic students' movement that favored Chinese control over some islands off the Vietnamese coast. The government approved of the students' objectives, but it simply would not permit organizational independence. Workers stand a poor chance of educating and organizing themselves under these conditions. As a result of this close control, the government benefited politically and big corporations benefited economically from the Nationalists' antiworker policies.

Taiwan, under martial law until 1987, does hold elections in which many working-class people participate as voters and, occasionally, as candidates. But elections do not give working-class people (or, indeed, most of the rest of the population) much voice in government for three reasons. First, a great deal of government power lies with the organs of the central government (those for all of China) rather than with the provincial and lower levels of government. Real power concentrates, therefore, in the hands of a very few Nationalist leaders close to the Jiang family, and the rest belongs to a representative body whose members were elected on the mainland in 1948 . In the seventies, as more and more of these aged legislators died in office, a few "at large" seats were permitted, which gave the majority Taiwanese population some additional seats. In the elections of 1980 , however, about 85 percent of the seats were still held by persons who represented mainland provinces and were generally out of touch with Taiwan's current conditions.

The second limitation on the democracy of Taiwan's elections is the prohibition against forming new political parties. Until 1986 the Nationalist party permitted only its own existence and that of two very small parties left over from Chinese mainland politics of the forties, which the Nationalists subsidize to avoid being called a one-party state. Candidates registered and ran as "outside the party," but were not permitted to support each other's candidacies even by appearing on the same platform. The fate of the new 


\section{Chinese Working-Class Lives}

Democratic Progressive Party, which emerged from this coalition, is still uncertain. Most outside-the-party candidates and voters are ethnically Taiwanese, while Mainlanders, even working-class ones, generally vote Nationalist.

Third, it is widely believed in Taiwan and reported in the international press that the Nationalists manipulate election results by ballot-box stuffing, vote buying, and intimidating popular candidates from running for election. Mr. Go, who does not like to discuss the matter, is believed to help in rounding up the local Nationalist vote in his neighborhood by distributing small payments; he is also known to have some muscle at his command, which makes people think twice before double-crossing him. A would-be outside-the-party candidate whom I knew slightly thought better of running against an unpopular Nationalist after his mother was threatened-not an uncommon sort of occurrence.

Elections, therefore, have proven a slow and fairly ineffectual means by which groups outside the inner circle of Mainlander elites may gain power. Although some Taiwanese have moved into high-ranking government and party positions in the 1970s and 1980s, they are usually party stalwarts and members of the economic upper class who do not represent working-class interests. The usual channels through which workers can come to understand and to affect the political system-unions and electoral politics - are blocked.

Nonetheless, resistance to Nationalist power repeatedly surfaces-sometimes clearly focused against the party, sometimes as a diffuse resentment of Mainlanders among Taiwanese. Resistance often takes apparently apolitical forms, such as antipollution demonstrations, which emphasize the solidarity of local communities and of the Taiwanese as a native-born ethnic group. Serious Mainlander opposition to the government, which has never been great, was suppressed by purges in the fifties and early sixties, though occasional defections of airplane pilots to the People's Republic of China, or complaints by poorly cared-for veterans of Jiang's original army, show that not all Mainlanders support the Nationalists.

Dissidence among intellectuals often takes the form of setting up a magazine to publish articles critical of the government until authorities crack down, ban or confiscate the publication, and send the most outspoken writers to jail. In the eighties, such intellectuals began to cooperate in increasing numbers, forming an opposition party. Novelists and short-story writers produce works of fiction that, by describing the lives of workingclass people, criticize the system more indirectly. Some young people, while studying abroad, acquire a greater understanding of Nationalist history, the utility of class analysis, and the socialist experiments of the 
People's Republic of China. Disillusioned, they respond differently to government and party when they return home (see Huang M. 1976).

Those who stand for the idea that Taiwan is a separate country and that all of its people should decide its political and economic future are labeled traitors and seditionists and punished accordingly. The Taiwan Independence Movement is therefore very much underground, or carried forward by small numbers of Taiwanese who have emigrated to Japan or the United States. Safely abroad, branches of the independence movement criticize the regime, attempting to persuade overseas Taiwanese to seek power at home and retain their Taiwaneseness while away. On one occasion, members of this group attempted to assassinate Jiang Jingguo (Jiang Jieshi's son) when he visited New York.

People who cannot be considered intellectuals yet who have considerable educational attainments, like $\mathrm{Mr}$. Kho, sometimes find oblique ways of expressing their alienation from Taiwan's power structure. At some risk, $\mathrm{Mr}$. Kho, who regrets the change from Japanese government, has rejected Mainlander reimposition of Chinese symbols by adopting a Japanese religion. Some Taiwanese symbolically reject Chinese authority by joining Christian churches with a reputation for sympathy with Taiwanese aspirations for greater local power.

But most working-class resistance takes different, less bookish, and less focused forms. The strength of working-class Taiwanese ethnic identity owes much to the people's participation in folk religion, which explicitly links the natives to the soil and history of the island. In 1980 I was told of the ever-growing presence at religious celebrations in the south of dozens, perhaps hundreds, of spirit mediums who show their spiritual powers by feats of self mutilation-piercing cheeks with skewers, beating backs with spiked balls, climbing "knife ladders," walking through hot coals-which left them uninjured. These practices are not new, but great gatherings of mediums drawing thousands of spectators represent a new trend. When mediums perform their bloody, horrifying acts, one thing they may be "saying" through their ritual is that Taiwanese have a kind of power that makes them invulnerable to mere physical force. Such symbolism is common in millenarian movements throughout the world, including China, as peoples who feel themselves oppressed seek the strength to reassert their power and reshape their societies (see, for example, Naquin 1976:30). The avid crowds who watch these spectacles are reminded that a society can draw on many different kinds of power, including those of numbers, group solidarity, and belief in themselves.

Resistance in Taiwan can assume more mundane forms as well, as $\mathrm{Mr}$. Kang's description of what goes on in Taiwan's political shadows indicates. 
Were the caches of guns and knives found by the police, which he mentions, intended for an underground resistance, or were they just gangsters' weapons? When Miss Ong's husband speaks mysteriously of the role his martial arts friends some day hope to have in "making life better for the poor," is politics involved, as there often is with Chinese gangs, or is he just, in the local phrase, "blowing cow?" I once heard a taxi driver deliver a very polished anticapitalist speech to my Taiwanese companions, who were amazed at his obvious attempt to involve them in something subversive. Sometimes an electric power plant or a government official is blown up, or a bomb is found on a bus. People have been told by the government that spies are everywhere, and I have myself met people who live beyond the edge of political safety, hoping only to accomplish a little more before being caught and sent to the infamous political prison on Green Island. And, in addition to local sources of dissent, it would be surprising if the island had not, in all these years, been infiltrated by Chinese from the Communist mainland, who have every reason to want to keep tabs on their old enemies.

The political situation continues to be further complicated, as it has been since 1945 , by the stated goal of the Chinese Communist party of reunifying China by reincorporating Taiwan into their nation. This possibility makes nationalist and independence advocates alike uneasy, for they assume that only a strong government armed with the latest in American military technology can prevent it. For many, anti-Communist fears excuse the dictatorial martial law that is often turned against the government's liberal critics. In response, the great majority of working-class people avoid national-level politics and political discussions, which they have been plainly told is none of their business. In the seventies and eighties, however, ordinary people have rioted against Nationalist vote fraud, burning police cars and demanding fairness for Taiwanese candidates. Recent elections have shown that for most voters, the real issue is not the choice of candidates, but the dominance of the party itself.

Politics in Taiwan is full of unanswered questions, or rumor and conjecture. Long-term American residents offer tips on how to recognize secret agents and how to get mail and manuscripts out of the country unread by the authorities; Chinese friends offer cryptic advice about speaking cautiously, or mention the oddities that intrigue Mr. Kang. A close associate pointed out the building where, in 1947, he had been tortured before a long imprisonment. The rumors give the island's atmosphere a taint of anxiety, even of paranoia; living there, one comes to fear there are horrid secrets that would be dangerous to know, acts or words that would result in swift and awful punishment. So while some resist, most keep silent, speak of other things, and construct for themselves little worlds of 
self-employment, neighborhoods, and families, where the dangerously "complicated" society can be kept at bay.

And so, in the 1980s, Taiwan balances economically between its own needs and those of America and Japan. Politically, it balances on shifting relationships between the United States and the People's Republic of China, and on those between ethnic groups in its own population. Its future is more uncertain than that of most countries, though uncertainty is the human condition everywhere. Many Mainlanders who can do so emigrate, usually to the United States, and even some Taiwanese legislators are believed to hold U.S. "green cards" for permanent residence here, in case of a takeover from the mainland. The ordinary folk of Taiwan, more than ever, live in the present, planning from decade to decade, or year to year"getting by." 